\title{
A wireless smart patch for the controlled repetitive transdermal administration of therapeutic agents
}

McConville, A., Atchison, J., Roddy, A., \& Davis, J. (2019). A wireless smart patch for the controlled repetitive transdermal administration of therapeutic agents. Sensors and Actuators B: Chemical, 294, 24-31.

https://doi.org/10.1016/j.snb.2019.05.023

Link to publication record in Ulster University Research Portal

\section{Published in:}

Sensors and Actuators B: Chemical

Publication Status:

Published (in print/issue): 01/09/2019

DOI:

10.1016/j.snb.2019.05.023

\section{Document Version}

Author Accepted version

\section{General rights}

Copyright for the publications made accessible via Ulster University's Research Portal is retained by the author(s) and / or other copyright owners and it is a condition of accessing these publications that users recognise and abide by the legal requirements associated with these rights.

\section{Take down policy}

The Research Portal is Ulster University's institutional repository that provides access to Ulster's research outputs. Every effort has been made to ensure that content in the Research Portal does not infringe any person's rights, or applicable UK laws. If you discover content in the Research Portal that you believe breaches copyright or violates any law, please contact pure-support@ulster.ac.uk. 


\section{Ulster}

\section{University}

\section{ELSEVIER}

(C) 2019. This manuscript version is made available under the CC-BY-NC-ND 4.0 license http://creativecommons.org/licenses/bync-nd/4.0/ 


\title{
A wireless smart patch for the controlled repetitive transdermal administration of therapeutic agents
}

\author{
Aaron McConville ${ }^{1 *}$, Jordan Atchison, Ashlene Roddy and James Davis \\ ${ }^{1}$ School of Engineering, Ulster University, Jordanstown, Northern Ireland, BT37 0QB, UK
}

\begin{abstract}
A thermoresistive transdermal drug delivery patch based on a n-alkane wax phase change film is described. A composite structure comprising a screen printed silver chloride heater sandwiched with a wax film loaded with diclofenac was developed and the release characteristics upon heating were investigated. The drug is shown to be immobile within the solid film (off state) but is readily delivered upon heating beyond the transition temperature $\left(37^{\circ} \mathrm{C}\right)$. Drug delivery is maintained while the heater is active and terminates upon cooling. The system has been shown to be capable of repetitive on-off cycling with control effected through a Bluetooth connection to a smart phone app with dynamic feedback control/thermoregulation of the patch.
\end{abstract}

\section{Keywords}

drug delivery; transdermal patch; thermal; heat enhanced; diclofenac

\footnotetext{
${ }^{1}$ To whom correspondence should be addressed. T: +44(0)28903 66823; E: a.mcconville@ulster.ac.uk
} 


\subsection{Introduction}

Transdermal patches have long held promise as a route through which therapeutic agents could be easily and painlessly delivered and self-administered on demand [1-3]. Given the capability of avoiding many of the issues associated with oral formulations and subcutaneous injections, it is little surprise that interest in these systems has grown considerably in recent years [4-8]. Transdermal delivery avoids many of the harmful side effects associated with oral ingestion and gastrointestinal irritation and as first pass hepatic degradation is bypassed, lower dosage of drugs is possible. The success of the delivery strategy is evidenced in part by the availability of numerous commercial products ranging from over the counter (OTC) nicotine $[9,10]$ patches through to prescription medicines such as estradiol [11], fentanyl [12,13], rivastigmine [14], rotigotine [15] and diclofenac $[16,17]$ covering hormone replacement therapy, chronic pain, dementia, Parkinson's disease and acute pain respectively. The commercialisation of transdermal drug patches has been progressing since 1979 and, while the nature of the therapeutic agent and entrapment matrices can vary widely, the underlying mechanism has remained relatively unchanged. In the vast majority of cases, drug delivery is achieved by passive diffusion from the patch reservoir across the stratum corneum through to the microcirculation[1-8]. As such, the rate of transfer is dependent on the formulation of the drug patch and, once initiated, there is little means of manipulating the dosing regime beyond the physical removal of the patch. The evolution of transdermal patches towards smarter, stimuli reactive, release dynamics has however gathered pace in recent years with mechanical actuation, electrical activation, light initiation and bioresponsive systems coming to the fore. These approaches have been comprehensively reviewed elsewhere [4-8] but, of the four classes mentioned, the electrical systems are perhaps the more readily adaptable for use in miniaturised closed loop dosing regimes. In this investigation, electrical control over the thermal properties of a phase change material is exploited as a means of controlling the dose yield and dose frequency of diclofenac.

Phase change materials (PCM) have been used in a wide variety of applications and typically transition from one phase to another upon the application of an appropriate stimulus. In this particular case, the PCM is based on a blend of alkanes which, at room temperature, will be solid but, upon heating rapidly transform to the liquid state[18-21]. Such materials are extensively used in large scale energy conversion applications as latent heat energy storage (LHES) systems $[18,19]$ 
but have also found application as actuators within microfluidic and microelectromechanical systems $[20,21]$. In such cases, the principal form of actuation is through the volume change associated with the transition from solid to liquid. The application of alkane based PCMs for transdermal drug delivery has yet to be explored and, in this investigation, the key mechanism is not volume change but rather the change in viscosity of the medium.

The delivery methodology is based on the preparation of a thin film of wax within which a model drug has been homogeneously distributed. At room temperature, the drug loaded wax will be solid and the entrapped drug is rendered essentially immobile. Upon heating the material, the wax becomes molten and the drug becomes free to move. The design approach adopted here involved combining a thin film of the wax-drug composite with a screen printed heater element which could be controlled via Bluetooth by an app from a smart phone as indicated in Figure $1 \mathrm{~A}$. The wax-drug composite is rinsed thoroughly with deionised water before assembly. This has the effect of removing loosely bound drug from the interface of the drug reservoir and thus, were the patch to be applied to the skin, the solid nature of the composite would prevent the transfer of any drug. Once the patch receives an appropriate signal from the smartphone app - the heater is initiated and the temperature increases to $45^{\circ} \mathrm{C}$. The wax will begin to transition from solid to liquid and, in doing so, the entrapped drug will become mobile. At this point, diffusion of the drug to the interface will occur (Figure 1B) and will be free to diffuse across the skin - much in the same way as a commercial OTC patch. The critical advance in this work is that the drug will continue to transfer as long as the wax is molten. A second (termination) signal sent by the smart phone switches off the heater and the material will re-solidify and the drug transfer will cease. Any drug remaining at the interface would be expected to transfer up to the point of phase transition whereupon there will be no drug in contact with the skin. A second dose could be applied to the patient through recommencing the heating process and thus the proposed strategy offers and ability to regulate repetitive dosing regimes and, in marked contrast to passive patches, enact complex delivery profiles for transdermal administration. 


\section{A}

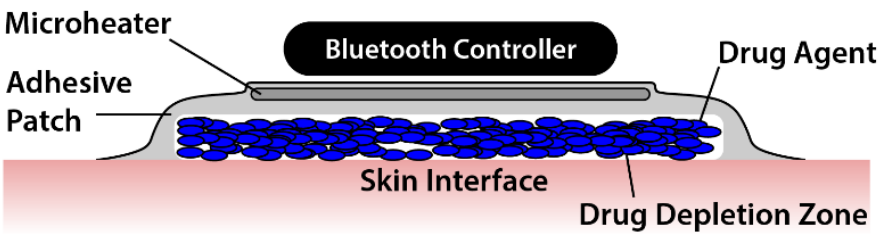

B

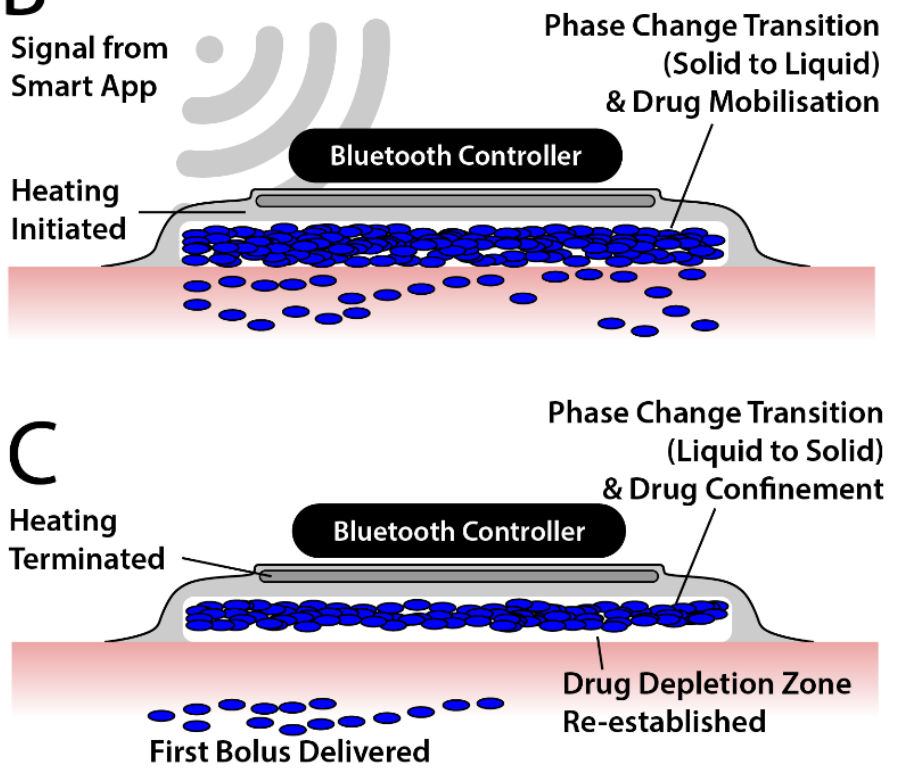

Figure 1. Schematic of the PCM-heater patch operation. (A) before activation the drug is immobile and not in contact with the skin. (B) Upon receiving an appropriate Bluetooth signal - the heat is initiated, phase change occurs and the drug is mobilised and able to transfer across the skin interface. (C) Once the heating cycle is terminated, phase change occurs as the system cools and the drug is once more rendered immobile.

In principle, as the heating element is based on a screen printed silver-silver chloride ink, the core system (with the exception of the Bluetooth receiver) would be disposable and thereby relatively inexpensive to deploy. The design rationale behind the system is presented and the ability of the prototype patch to deliver diclofenac was investigated.

\subsection{Experimental Details}

\subsection{Materials}

Toluidine Blue O, paraffin wax pellets (76242), and diclofenac sodium were obtained from SigmaAldrich Company Ltd (Dorset, England). A 50:50 Ag/AgCl paste (C2000215P4) with a solids content 
of $81.14-83.14 \%$ (at $130^{\circ} \mathrm{C}$ ) was supplied by Gwent Electronic Materials Ltd. (Pontypool, UK). All chemicals purchased were of analytical grade and used without any further purification.

\subsection{Microheater Fabrication}

A spiral-shaped microheater was designed using the DraftSight 2D CAD package (Dassault Systèmes), with a track width of $1 \mathrm{~mm}$ and effective heating area of $14 \times 14 \mathrm{~mm}$. A screen manufactured by ASM Assembly Systems (Dorset, England) was used in conjunction with a DEK 240 manual screen printer to print the microheaters onto acetate sheets using $\mathrm{Ag} / \mathrm{AgCl}$ paste. The printed microheaters were then heated in an oven at $120^{\circ} \mathrm{C}$ for $600 \mathrm{~s}$ to ensure full solvent evaporation. Scanning electron micrographs detailing the surface morphology of the heater are shown in Figure 2.

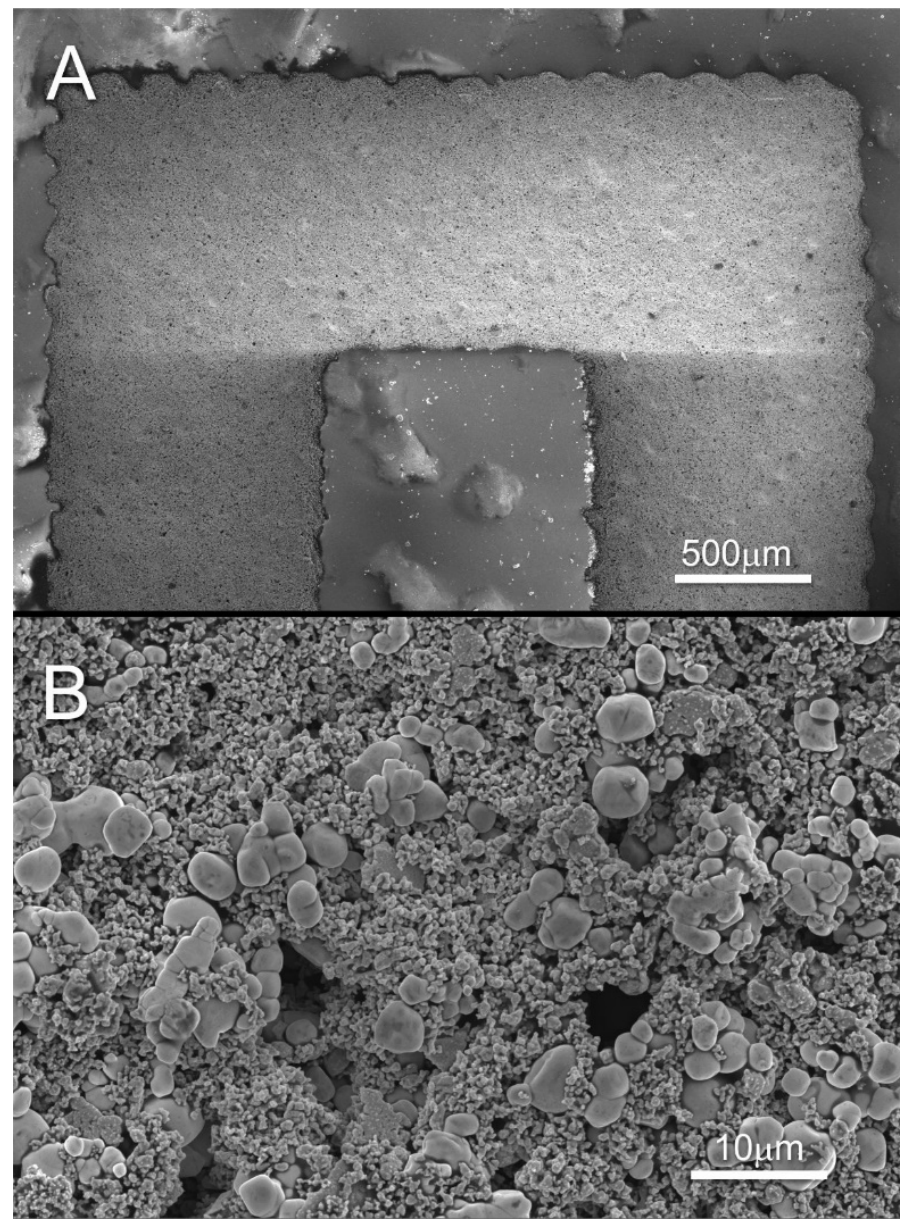

Figure 2. Scanning electron micrographs of the printed heater highlighting the granular nature of the silver-silver chloride deposit. 


\subsection{Feedback Loop}

In order to maintain near constant temperature, a feedback loop was designed in $\mathrm{C}++$ and implemented using an Arduino Nano ATmega328P microcontroller board and Melexis MLX90614 non-contact infrared thermometer. The microcontroller board was powered using a microUSB cable in conjunction with a 5V USB mains power adapter, whilst the heater derived power from an external bench top power supply, operated in continuous current mode. The desired temperature was selected by adjustment of a potentiometer, with target and current temperatures, as well as time elapsed displayed on a 128x64 OLED display module. A single channel $5 \mathrm{~V}$ relay was used to modulate current flowing from the external power supply to the microheater, with switching handled by the aforementioned microcontroller board. Upon actuation of a heating cycle, the microcontroller board begins to read values from the non-contact infrared thermometer. By comparing the actual temperature readings to the target temperature set, the relay is switched on or off so as to continue or discontinue heating, thus enabling the predefined target temperature to be maintained. A sufficient sampling rate was implemented to prevent deviation of more than $0.25^{\circ} \mathrm{C}$ from the target set.

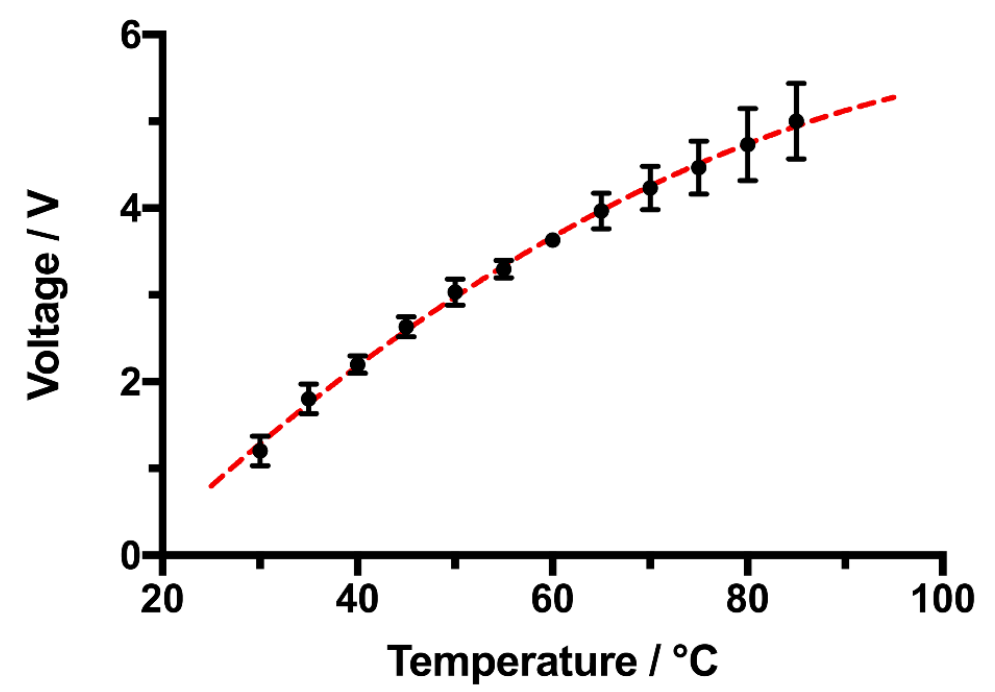

Figure 3. Influence of applied voltage on the temperature recorded at the screen printed heater element. $(\mathrm{N}=3)$. Temperature measured with an infra-red probe directed at the acetate substrate. 


\subsection{Bluetooth Actuation}

To engage a pre-programmed heating cycle, an Android application was designed. The Arduino Nano ATmega328P microcontroller board was coupled with a HC-06 module, featuring a Cambridge Silicon Radio BC417 2.4 GHz Bluetooth radio chip, enabling wireless communication between the Android device and heating system. Following connection to the on-board Bluetooth module, the user is presented with a number of drug delivery profiles, allowing frequency and dosage to be adjusted within a pre-defined limit. Visual confirmation of the delivery profile is provided on the display module following selection.

\subsection{Fabrication of the Drug Patch}

The phase change material is based on a blend of hydrocarbons traditionally used in commercial cosmetic applications and, at room temperature, is present in the form of a wax. At temperatures approaching $45^{\circ} \mathrm{C}$, the wax transitions from solid to liquid. Diclofenac was used as the model drug given its analgesic properties and the fact that there are commercial diclofenac transdermal patches already available $[16,17]$. It is also extensively used as a model in the development of transdermal patch systems - those relying on purely passive transfer [22-24] and those exploiting physical enhancement such as heat or iontophoresis [25]. The sodium salt of diclofenac was mixed with the molten wax and stirred until homogenously distributed. An aliquot of the molten wax $(600 \mu \mathrm{L})$ was pipetted in a circular holder $(\varnothing 18 \times 2 \mathrm{~mm}$ ) and allowed to cool resulting in a thin solid film. The wax disc was then washed with copious amounts of deionised water. The hydrophobic nature of the wax disc prevents penetration of the water into the core and thus only diclofenac present at the immediate interface is removed. The screen printed heater was placed with the unprinted acetate side in contact with the wax film. Thus, the application of an appropriate voltage led to the generation of heat directly on the acetate sheet but without the drug being in contact with the electrical circuit.

\subsection{Drug Release Studies}

A Franz cell chamber was employed for the drug release studies and the typical assembly is highlighted in Figure 4. The drug loaded wax patch was placed directly in contact with the receiving solution (deionised water) and the heater laminate placed on top of the patch. The transfer of the drug into the receiving chamber solution was determined through extracting 
samples from the receiving arm and using UV-Vis spectroscopy to identify changes after each heat-cool cycle. The receiving solution was maintained at $22^{\circ} \mathrm{C}$.

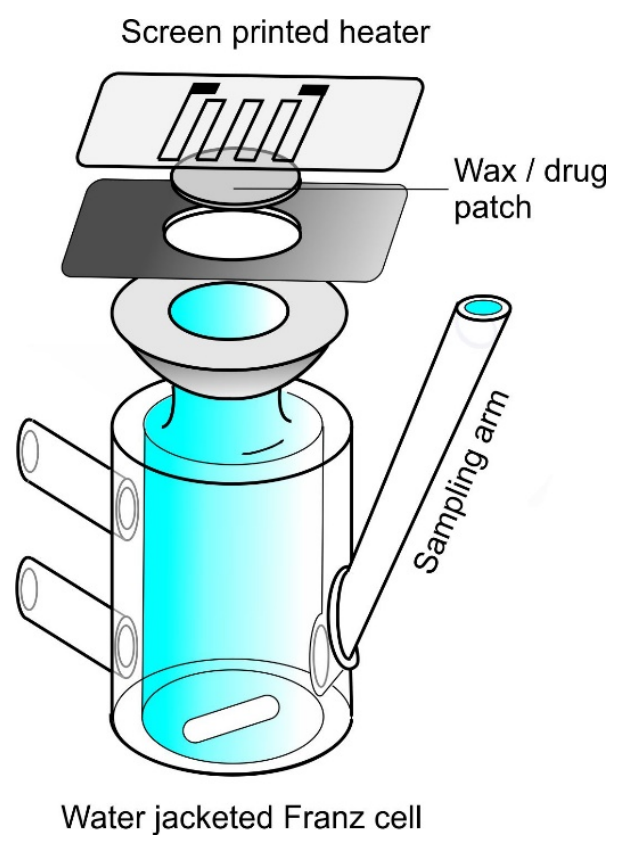

Figure 4. The patch system was mounted on a conventional Franz cell which enabled sampling of the receiving volume for spectroscopic analysis.

\subsection{Results and Discussion}

Toluidine Blue-O (TBO) was initially chosen as a model drug through which to assess the release characteristics of the patch. The dye provides simple but sensitive visual confirmation with the prime chromophore peak process observed at $589 \mathrm{~nm}\left(\varepsilon=7.75 \times 10^{4} \mathrm{~L} \mathrm{~mol}^{-1} \mathrm{~cm}^{-1}\right)$. The heated patch system was mounted on a conventional Franz cell without any separation membrane and thus the wax was in direct contact with the aqueous layer in the receiving chamber. The hydrophobicity of the wax prevented dissolution into the latter and, providing the interface was rigorously washed prior to placement, no transfer of TBO to the solution was observed. This was confirmed through exposing the wax-TBO composite interface to the aqueous layer and the receiving solution sampled at regular intervals over a period of 2 hours. There was no change in UV-Vis spectra over the analysis period indicating that no leaching of the dye had occurred. 
It was anticipated that activation of the heating element in contact with the wax patch would raise the temperature of the wax beyond its transition temperature $\left(37^{\circ} \mathrm{C}\right)$ resulting in a solid to liquid transition. Once molten, it can be envisaged that the entrapped drug will be capable of movement as a consequence of diffusion within the liquid wax. This process should lead to an increase in the drug concentration at the interface between the receiving solution and the wax and hence the delivery of the drug to the former. One of the key challenges therefore relates to the control of the heating component which will influence delivery rate and drug yield. A critical underpinning factor is the temperature of the patch as this will induce the mobilisation of the drug and its transfer but must also be sufficiently low as to preclude damaging the skin of the patient.

The temperature of the device can be controlled through a variety of design factors but the aim here is not to provide an exhaustive exploration of these but rather to demonstrate proof of principle for the proposed mechanism. As such, a single element design was chosen and the heat regulated through controlling the current through the resistive printed layer. A preliminary assessment of the heater/patch assembly was performed using two current configurations: 100 $\mathrm{mA}$ and $120 \mathrm{~mA}$. These were selected on the basis that both demonstrated an ability to reach the transition temperature of the wax relatively quickly - typically within 60 seconds of activation. A wax patch containing $5 \%$ wt. drug was used as an initial model through which to investigate the thermal performance of the prototype devices and determine the release characteristics. The devices were assembled as per the schematic highlighted in Figure 4 and the heating element activated for a period of $180 \mathrm{~s}$. A cooling period of $180 \mathrm{~s}$ was then employed before repeating the cycle. The data obtained for the heater running at $100 \mathrm{~mA}$ and $120 \mathrm{~mA}$ over a series of 5 consecutive cycles is detailed in Figure 5. 


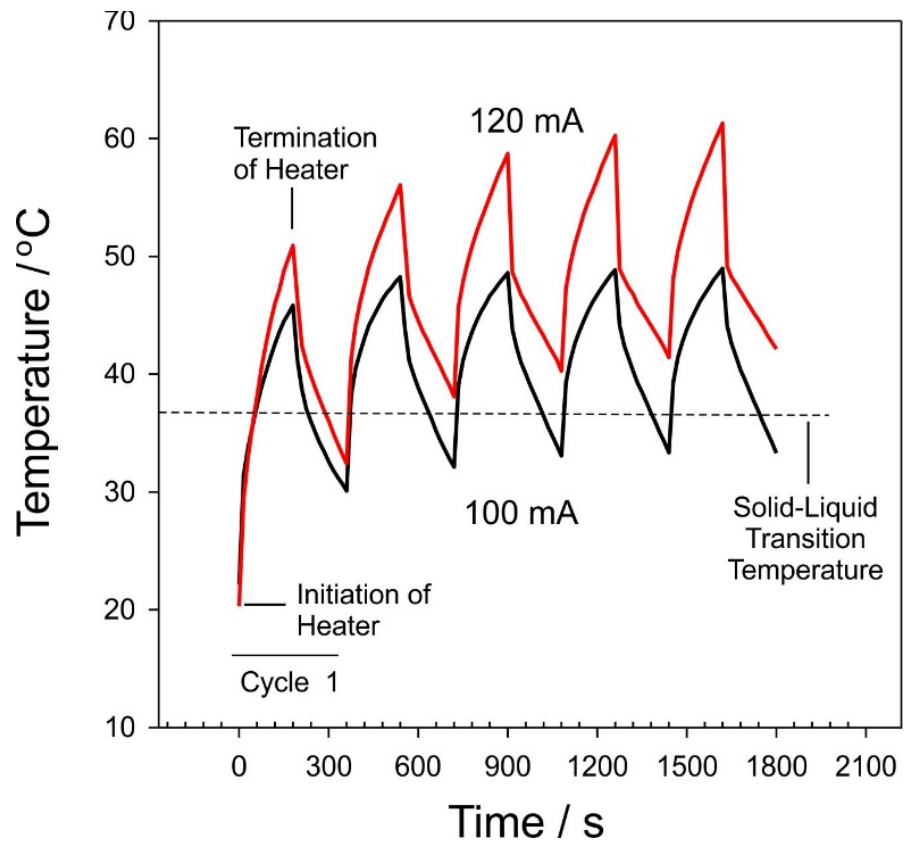

Figure 5. Temperature change in response to current applied at $100 \mathrm{~mA}$ and $120 \mathrm{~mA}$, demonstrating ramping effect in open-loop configuration.

The transition temperature is reached within $60 \mathrm{~s}$ of activation from ambient temperatures $\left(22^{\circ} \mathrm{C}\right)$ and it can be seen that the temperature of the wax continues to rise until the applied current is terminated. At this point the wax begins to cool and re-solidify. The temperature decreases but it can take in excess of 15 minutes (for the $100 \mathrm{~mA}$ system) to return to ambient. The greater the applied current the greater the temperature increase. In order to confirm that the drug is indeed mobilised during these heating cycles, UV-Vis spectra of the receiving solution were recorded immediately prior to the commencement of next heating cycle. The spectra obtained for the 100 $\mathrm{mA}$ system are detailed in Figure 6A and a quantitative comparison of the $100 \mathrm{~mA}$ and $120 \mathrm{~mA}$ systems is shown in Figure 6B.

There is a cumulative increase in the absorbance corresponding to the released TBO with each cycle. It should be noted that when the heating cycles are terminated (at least in the case of the $100 \mathrm{~mA}$ system) - no further increase in the absorbance band at $589 \mathrm{~nm}$ is observed confirming that the phase change process is critical for mobilising the drug and facilitating its transfer to the receiving solution. 

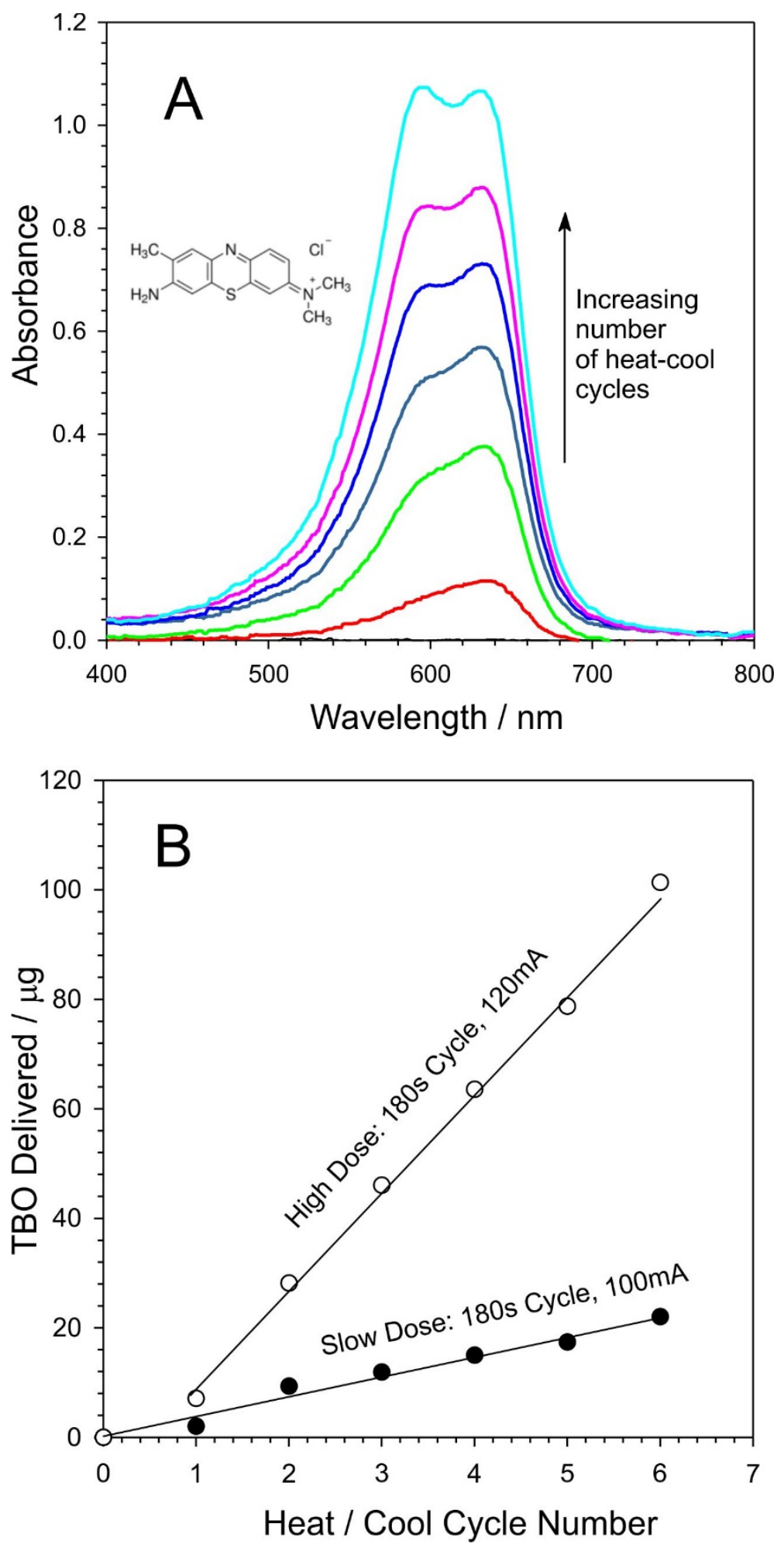

Figure 6. (A) UV-Vis spectrum demonstrating increasing absorbance in the presence of TBO following each dosing cycle at $120 \mathrm{~mA}$. (B) The influence of applied current on the amount of drug released during a given release cycle. 
There is a dramatic difference between the 100 and $120 \mathrm{~mA}$ systems and it could be tempting to suggest that the delivery yield could be controlled through manipulation of the applied current. Examination of the data presented in Figure 5 highlights a number of issues with such an assumption. Taking the first cycle as an example - in the case of the $120 \mathrm{~mA}$ system, the temperature increases quicker and the cooling period is longer such that the wax is in a molten state for longer than the $100 \mathrm{~mA}$ system and therefore there is more opportunity for the drug to be transferred to the aqueous solution and hence the yield, as highlighted in Figure 6B, is greater. However, the temperature has risen considerably beyond what would be considered a safe level for direct application to human skin. In this particular scenario, the short duration of the cycles has meant that on subsequent cycles, the cooling phase fails to return below the transition temperature and hence the drug continues to be delivered. The $100 \mathrm{~mA}$ system, in contrast, reaches the maximum temperature limit of $45^{\circ} \mathrm{C}$ in the first cycle within the $180 \mathrm{~s}$ heating duration. The cooling period is still too short however and there is an emergence of a temperature ramp with each subsequent cycle - rising to $48{ }^{\circ} \mathrm{C}$ by the end of cycle 5 . In practical terms the cooling period can be longer to allow the return to ambient but there is a clear restriction in terms of the heating cycle and hence the amount that can be delivered. Analysis of the UV-Vis spectra reveals that the average amount of drug delivered per cycle (at $100 \mathrm{~mA}$ ) is $3.13 \mu \mathrm{g} \pm 0.596 \mu \mathrm{g}$. Increasing the drug yield through increasing the duration over which the heater is activated in this simple system would mean that the temperature will also rise beyond the $45^{\circ} \mathrm{C}$ limit.

The simple unregulated application of a constant current to the heater is clearly untenable for the proposed application. It is clear that while the use of phase change material can enable repetitive dosing through the application of a heating cycle, additional protective measures would be required to ensure that the temperature does not exceed the safety limit. A feedback circuit was constructed based on the integration of a Melexis non-contact IR sensor and associated control circuit (detailed within the supporting information) and software. This limits the current such that the temperature is fixed at $45^{\circ} \mathrm{C}$. A comparison between the unregulated and feedback systems for the $120 \mathrm{~mA}$ configuration over 5 cycles is shown in Figure 7. 


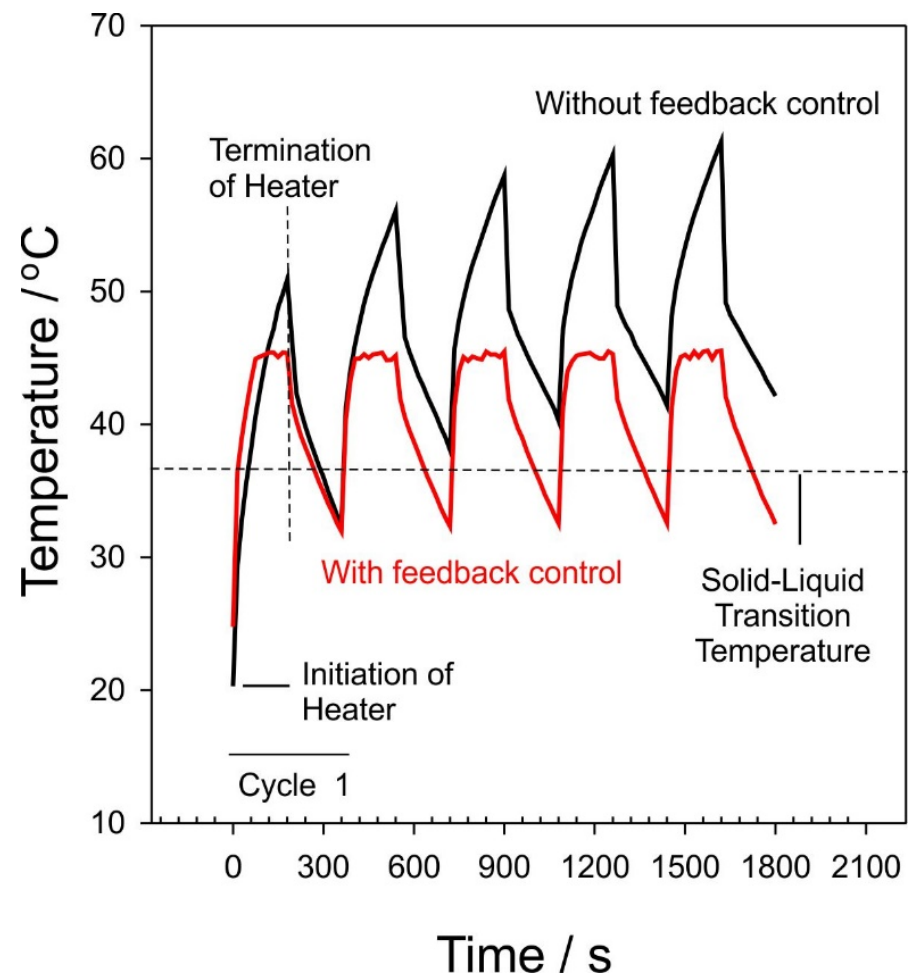

Figure 7. Effects of repeated heating and cooling cycles, with and without feedback control implementation.

While the temperature of the unregulated system ramps significantly with increasing cycles, the feedback system maintains a peak temperature of $45^{\circ} \mathrm{C}$ throughout as indicated in Figure 7 and detailed in Table 1. The temperature variation within a given cycle at the peak temperature was found to be 0.05 (based on $N=5$ ), with 8 discrete values recorded during the plateau of each cycle.

\begin{tabular}{c|c|cccc} 
& $\begin{array}{c}\text { Unregulated } \\
\text { System } \\
\text { Cycle }\end{array}$ & \multicolumn{4}{|l}{ Feedback Regulated System } \\
\hline 1 & 50.93 & 45.41 & 8 & 45.24 & 0.066 \\
2 & 56.05 & 45.39 & 8 & 45.14 & 0.069 \\
3 & 58.71 & 45.47 & 8 & 45.18 & 0.070 \\
4 & 60.27 & 45.49 & 8 & 45.23 & 0.059 \\
5 & 61.29 & 45.53 & 8 & 45.31 & 0.086 \\
\hline
\end{tabular}

Table 1. Comparison of unregulated and feedback control on temperature of the wax film 
The introduction of the feedback system effectively removes the option of controlling the rate of release through the manipulation of the current but, crucially, it proffers an opportunity to facilitate drug release beyond $180 \mathrm{~s}$ and thereby enable increased boluses to be attained without the risk of thermal damage to the skin.

The modified feedback system combined with Bluetooth control was further evaluated using diclofenac as a target drug. Diclofenac is a common analgesic that is already used in transdermal patch systems and therefore serves as an ideal test to the system. The drug was incorporated into the wax through the same procedures as those used with TBO and the resulting thin film washed and mounted in the Franz cell along with the Bluetooth controlled heater circuit. The receiving solution was sampled every 10 minutes and the absorbance spectra analysed for the presence of diclofenac. The latter lacks any visible chromophore and, as such, its release was detected through the increase in absorbance at $279 \mathrm{~nm}$. It must be noted that the paraffin wax is predominantly saturated hydrocarbon with no appreciable UV active groups and thus presents no direct interference to the measurement. Under conditions in which the heater was dormant, no release of the diclofenac into the receiving chamber was observed. In contrast, the activation of the heater $\left(45^{\circ} \mathrm{C}\right)$ results in the transport of the diclofenac with the heat-cool cycles resulting in cumulative dosing. A quantitative comparison highlighting the drug release under active and dormant actions is detailed in Figure 8. 


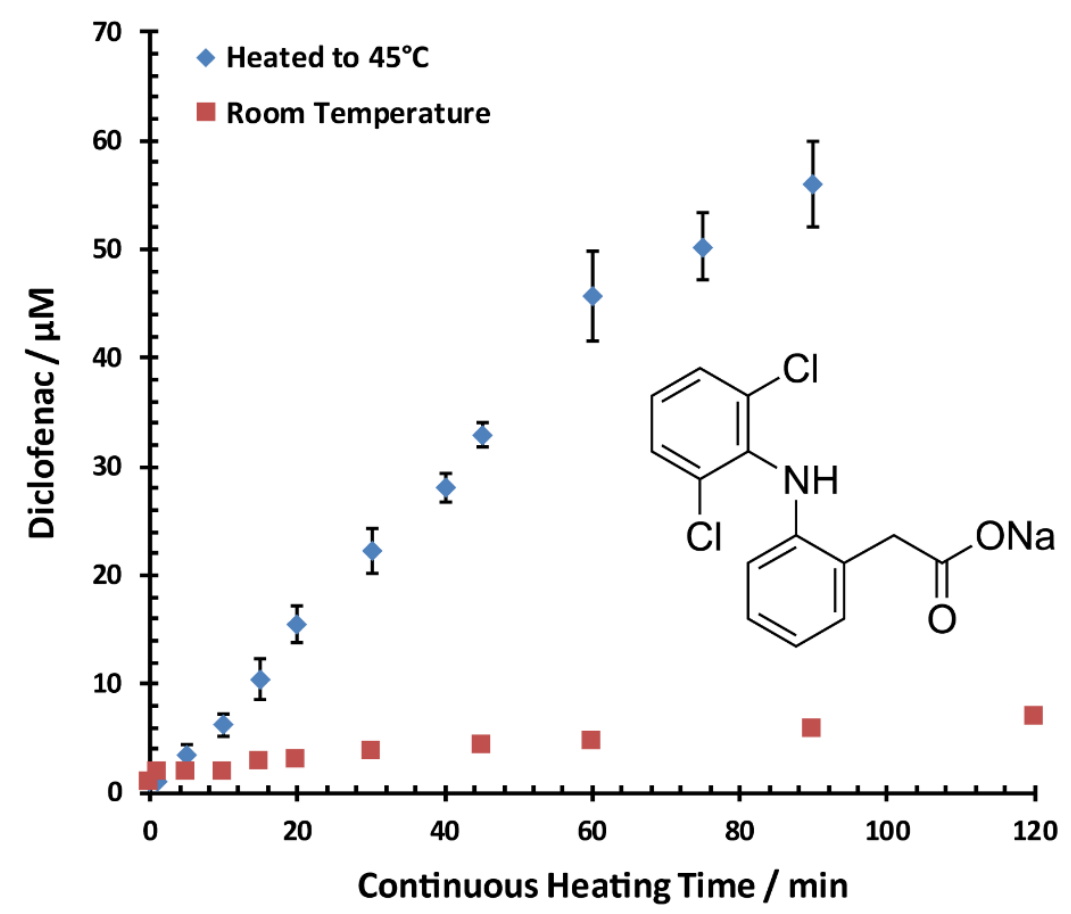

Figure 8. Comparison in release of diclofenac sodium $(\mu \mathrm{M})$ over time when heated to $45^{\circ} \mathrm{C}$ and at room temperature $\left(20^{\circ} \mathrm{C}\right)$

A quantitative comparison of the drug released per 10 minute cycle is detailed in Figure 9 (based on 3 individual patches).

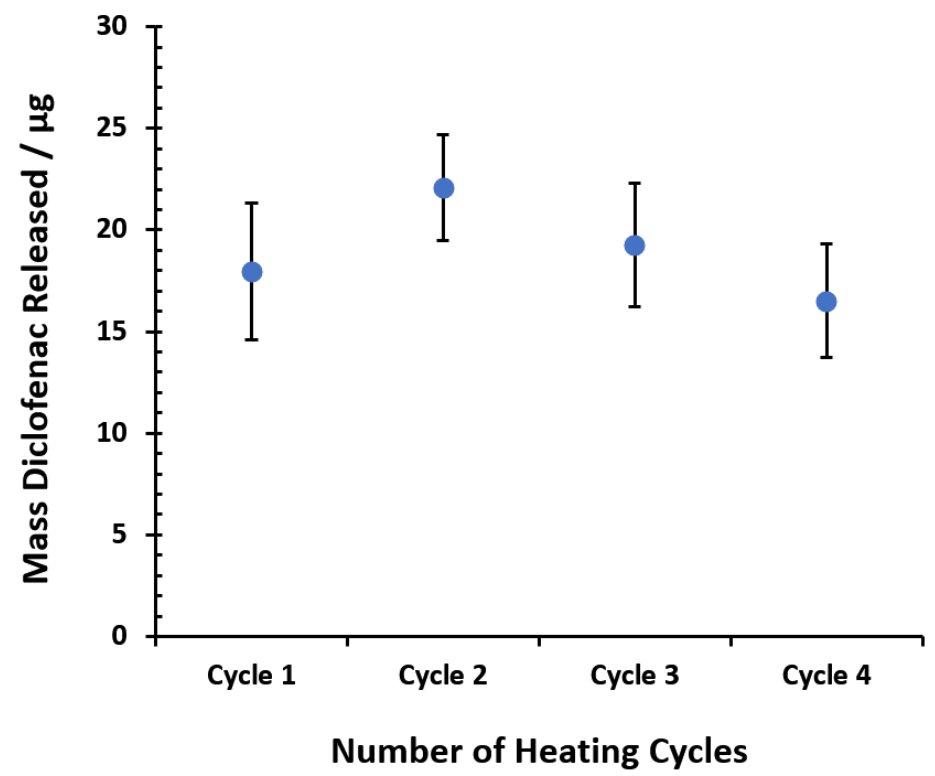

Figure 9. Diclofenac Sodium release $(\mu \mathrm{g})$ per 10 minute heating/cooling cycle. 
It was also necessary to assess the effect of the drug loading and release on the thermal dynamics of the proposed patch to determine if the presence of the drug unduly comprised the solid-liquid transition. Three patches containing different loadings of diclofenac $(1-10 \%)$ were assessed to determine how the increased loading would affect the temperature response. The data for three samples is highlighted in Figure 10 and it can be seen that the response is relatively independent of the drug loading.

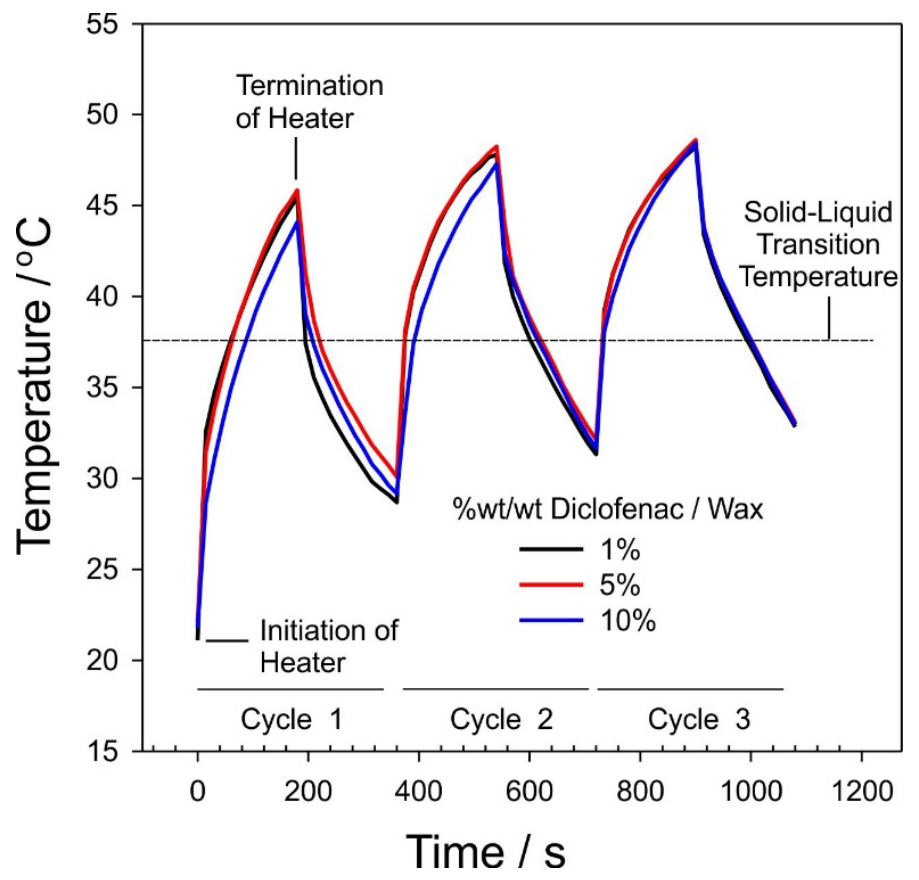

Figure 10. Effects of drug loading on temperature during heating and cooling cycles.

\section{Discussion}

It has been shown that increasing the skin temperature from a baseline $32{ }^{\circ} \mathrm{C}$ by $9-13{ }^{\circ} \mathrm{C}$ leads to a 6-7 fold increase in local blood flow $[26,27]$ and results in structural changes within the stratum corneum that affect the diffusion, partitioning and barrier properties of the skin. Increasing the skin temperature between 35 and $42{ }^{\circ} \mathrm{C}$ is known to disrupt the ceramides, fatty acids, cholesterol and its associated esters that form the lipid bilayers [28-31]. At $37^{\circ} \mathrm{C}$ the lipids covalently bonded to the corneocytes are disrupted and there is a solid to fluid transition [32-34] 
which results in increased conformational freedom in the lipid bilayer. The latter is often cited as the reason for increased drug partitioning [35] and therein facilitates increased skin absorption of potential drugs but, it has to be noted, that the effect of heat on transdermal drug delivery is further complicated by the widely varied designs and formulations used in patches. The behaviour of chemically distinct patch components, either individually or within a complex formulation mixture combined within an equally complex and variable skin structure are difficult to anticipate and a generic model is elusive. It is however clear that variations in local of skin temperature can therefore dramatically impact the clinical efficacy and/or safety of transdermal and topical drug products. Wood et al. (2012) for example demonstrated that increased partitioning of lidocaine base into the epidermis and increased epidermal diffusion were observed at $45^{\circ} \mathrm{C}$ as compared with that at $32{ }^{\circ} \mathrm{C}$ with a $519 \%$ boost in diffusivity [31]. Although subjects have reported discomfort when in direct contact with a heat source upon reaching $43^{\circ} \mathrm{C}$, with the potential for skin damage occurring following a further increase of $1-2{ }^{\circ} \mathrm{C}$, it has been estimated that such damage is minimal and likely to be transient $[36,37]$. Otto et al. (2014) report that temperatures of up to $45{ }^{\circ} \mathrm{C}$ are "physiologically tolerable to the human skin" [38], with a number of heatassisted drug permeation studies such as that carried out by Akomeah et al. (2004) limiting their temperature range to $45^{\circ} \mathrm{C}$ so as to "minimise thermal damage to the skin" [39]. It is important to note that the heat source and infrared sensor within the Wax PCM patch are not in direct contact with the skin, but rather on the outer side of the wax disc. Therefore, it can be anticipated that the temperature at the wax-skin interface will be somewhat lower than that of the waxheater interface, minimising the potential for skin damage. Should the melting point of the wax used in the current investigation be deemed too high, posing risk to the patient, an alternative blend of hydrocarbon waxes with a lower melting point may be employed in its place. Skin temperature under normal conditions will be dependent on a host of factors but typically resides around $33^{\circ} \mathrm{C}$ and has been shown to rise to around $40{ }^{\circ} \mathrm{C}$ during exercise in a hot environment [40-42], and it is obvious that fluctuations in local heat could result in the variations in dosing which could be detrimental to the patient.

Rather than being the passively susceptible to spikes in drug dosing, one option is to actively control the temperature by raising the patch beyond the ambient surrounding. The active use of heat as a method through which to enhance percutaneous drug absorption has a long history (Blank et al, 1967) but its practical application has failed to acquire significant commercial support 
[43]. Synera ${ }^{\mathrm{TM}}$, a transdermal patch for the delivery of lidocaine and tetracaine, is one of the few successful entries and utilises an integral chemical heat pad $\left(\mathrm{CHADD}^{\mathrm{TM}}\right)$ based on the air oxidation of iron powder to raise the temperature to around $40-41^{\circ} \mathrm{C}[44,45]$. It could similarly be expected that the application of the Wax PCM patch investigated here would similarly benefit from the increased temperature enhancing drug transfer through the skin and the electronic regulation of the temperature helping to eliminate the variations (and hence dosage spikes) that can beset simpler systems.

The direct application of heat as a means of initiating the release of drugs rather than simply controlling the rate of release has begun to generate interest - particularly through advances in microdevice development and responsive materials. Miniaturised electro-resistive heaters [4652] and photothermal systems $[53,54]$ are two of the current methodologies with the Wax PCM patch falling within the remit of the former. Printed heater systems have been shown to be particularly amenable to wearable applications through their inherent flexibility and ability to conform to the variable surface morphologies of the skin. As the resistance of a material is proportional to length and cross-sectional area, the heating profile of the microheater can be maintained whilst scaling the effective heating area, assuming both factors are also scaled accordingly. These are typically employed alongside thermo-responsive micro/nano particulate carriers which undergo a structural change (swelling, shrinking, dissolution) upon reaching a critical temperature and therein release the drug. These devices typically employ discrete micro structures and it could be argued that the wax film offers a far simpler approach (compositionally and procedurally) to the fabrication of the devices. The critical advantage however is the ability to initiate repetitive dosing cycles through the repeated cooling (off) and heating (on) cycles.

\section{Conclusions}

Transdermal drug delivery offers a great number of advantages over conventional oral and injection methods but the variability of the skin interface, ambient conditions and local heat arising through activity are factors that affect the delivery rate. Moreover, many of the patch systems invoke passive transfer upon application while there is an increasing demand for devices that can provide a drug bolus upon activation of a specific trigger. There is considerable interest 
in the development of thermal activation and the wax film matrix described here adopts this methodology and provides a simple route through which drug release can be initiated, maintained with controllable on-off cycling over protracted periods.

\section{Acknowledgements}

The authors thank the Department for the Economy (DfE) Northern Ireland for supporting this work.

\section{References}

[1] M.R. Prausnitz, S. Mitragotri, R. Langer, Current status and future potential of transdermal drug delivery., Nat. Rev. Drug Discov. 3 (2004) 115-124. doi:10.1038/nrd1304.

[2] J. Hadgraft, M.E. Lane, Passive transdermal drug delivery systems, Am. J. Drug Deliv. 4 (2006) 153160. doi:10.2165/00137696-200604030-00003.

[3] M.R. Prausnitz, R. Langer, Transdermal drug delivery., Nat. Biotechnol. 26 (2008) 1261-1268. doi:10.1038/nbt.1504.

[4] M. Amjadi, S. Sheykhansari, B.J. Nelson, M. Sitti, Recent Advances in Wearable Transdermal Delivery Systems., Adv. Mater. 30 (2018). doi:10.1002/adma.201704530.

[5] I. Hwang, H.N. Kim, M. Seong, S.-H. Lee, M. Kang, H. Yi, W.G. Bae, M.K. Kwak, H.E. Jeong, Multifunctional Smart Skin Adhesive Patches for Advanced Health Care., Adv. Healthc. Mater. 7 (2018) e1800275. doi:10.1002/adhm.201800275.

[6] C. Strasinger, S.G. Raney, D.C. Tran, P. Ghosh, B. Newman, E.D. Bashaw, T. Ghosh, C.G. Shukla, Navigating sticky areas in transdermal product development., J. Control. Release. 233 (2016) 1-9. doi:10.1016/j.jconrel.2016.04.032.

[7] L.F. Santos, I.J. Correia, A.S. Silva, J.F. Mano, Biomaterials for drug delivery patches, Eur. J. Pharm. Sci. 118 (2018) 49-66. doi:10.1016/j.ejps.2018.03.020.

[8] H. Lee, C. Song, S. Baik, D. Kim, T. Hyeon, D.-H. Kim, Device-assisted transdermal drug delivery., Adv. Drug Deliv. Rev. 127 (2018) 35-45. doi:10.1016/j.addr.2017.08.009.

[9] J. Handschin, B. Hitsman, S. Blazekovic, A. Veluz-Wilkins, E.P. Wileyto, F.T. Leone, R.L. Ashare, R.A. Schnoll, Factors Associated with Adherence to Transdermal Nicotine Patches within a Smoking Cessation Effectiveness Trial, J. Smok. Cessat. 13 (2018) 33-43. doi:DOI: 10.1017/jsc.2017.2.

[10] S.H. Shin, S. Thomas, S.G. Raney, P. Ghosh, D.C. Hammell, S.S. El-Kamary, W.H. Chen, M.M. Billington, H.E. Hassan, A.L. Stinchcomb, In vitro-in vivo correlations for nicotine transdermal 
delivery systems evaluated by both in vitro skin permeation (IVPT) and in vivo serum pharmacokinetics under the influence of transient heat application., J. Control. Release. 270 (2018) 76-88. doi:10.1016/j.jconrel.2017.11.034.

[11] A. Bertonazzi, B. Nelson, J. Salvador, E. Umland, The smallest available estradiol transdermal patch: a new treatment option for the prevention of postmenopausal osteoporosis., Womens. Health (Lond. Engl). 11 (2015) 815-824. doi:10.2217/whe.15.64.

[12] C. Padula, S. Pescina, S. Nicoli, P. Santi, Generic patches containing fentanyl: In vitro equivalence and abuse deterrent evaluation according to EMA and FDA guidelines., Int. J. Pharm. 537 (2018) 57-63. doi:10.1016/j.ijpharm.2017.12.031.

[13] J.S. Ahn, J. Lin, S. Ogawa, C. Yuan, T. O'Brien, B.H.C. Le, A.M. Bothwell, H. Moon, Y. Hadjiat, A. Ganapathi, Transdermal buprenorphine and fentanyl patches in cancer pain: a network systematic review, J. Pain Res. 10 (2017) 1963-1972. doi:10.2147/JPR.S140320.

[14] M.K. Malaiya, A. Jain, H. Pooja, A. Jain, D. Jain, Controlled delivery of rivastigmine using transdermal patch for effective management of alzheimer's disease, J. Drug Deliv. Sci. Technol. 45 (2018) 408-414. doi:10.1016/J.JDDST.2018.03.030.

[15] T. Müller, E. Tolosa, L. Badea, M. Asgharnejad, F. Grieger, M. Markowitz, X. Nondonfaz, L. Bauer, L. Timmermann, An observational study of rotigotine transdermal patch and other currently prescribed therapies in patients with Parkinson's disease, J. Neural Transm. 125 (2018) 953-963. doi:10.1007/s00702-018-1860-x.

[16] S. Drago, R. Imboden, P. Schlatter, M. Buylaert, S. Krahenbuhl, J. Drewe, Pharmacokinetics of Transdermal Etofenamate and Diclofenac in Healthy Volunteers., Basic Clin. Pharmacol. Toxicol. 121 (2017) 423-429. doi:10.1111/bcpt.12818.

[17] P.G. Xu, X.F. Lei, B. Di Ren, S.Y. Lv, J.L. Zhang, Diclofenac transdermal patch versus the sustained release tablet: A randomized clinical trial in rheumatoid arthritic patients, Trop. J. Pharm. Res. 16 (2017) 477-482. doi:10.4314/tjpr.v16i2.29.

[18] H. Peng, D. Zhang, X. Ling, Y. Li, Y. Wang, Q. Yu, X. She, Y. Li, Y. Ding, n-Alkanes Phase Change Materials and Their Microencapsulation for Thermal Energy Storage: A Critical Review, Energy \& Fuels. 32 (2018) 7262-7293. doi:10.1021/acs.energyfuels.8b01347.

[19] S.N. Gunasekara, V. Martin, J.N. Chiu, Phase equilibrium in the design of phase change materials for thermal energy storage: State-of-the-art, Renew. Sustain. Energy Rev. 73 (2017) 558-581. doi:https://doi.org/10.1016/j.rser.2017.01.108.

[20] S. Ogden, L. Klintberg, G. Thornell, K. Hjort, R. Bodén, Review on miniaturized paraffin phase change actuators, valves, and pumps, Microfluid. Nanofluidics. 17 (2014) 53-71. doi:10.1007/s10404-013-1289-3.

[21] E. Wilhelm, C. Richter, B.E. Rapp, Phase change materials in microactuators: Basics, applications 
and perspectives, Sensors Actuators A Phys. 271 (2018) 303-347.

doi:https://doi.org/10.1016/j.sna.2018.01.043.

[22] R.S.H. Wong, K. Dodou, Effect of Drug Loading Method and Drug Physicochemical Properties on the Material and Drug Release Properties of Poly (Ethylene Oxide) Hydrogels for Transdermal Delivery, Polym. . 9 (2017). doi:10.3390/polym9070286.

[23] C. Liu, P. Quan, L. Fang, Effect of drug physicochemical properties on drug release and their relationship with drug skin permeation behaviors in hydroxyl pressure sensitive adhesive., Eur. J. Pharm. Sci. 93 (2016) 437-446. doi:10.1016/j.ejps.2016.08.048.

[24] N. Ercan, M.O. Uludag, E.R. Agis, E. Demirel-Yilmaz, The anti-inflammatory effect of diclofenac is considerably augmented by topical capsaicinoids-containing patch in carrageenan-induced paw oedema of rat., Inflammopharmacology. 21 (2013) 413-419. doi:10.1007/s10787-013-0175-7.

[25] H. Patel, A. Joshi, A. Joshi, G. Stagni, Effect of microporation on passive and iontophoretic delivery of diclofenac sodium., Drug Dev. Ind. Pharm. 41 (2015) 1962-1967. doi:10.3109/03639045.2015.1019353.

[26] N.E. Freeman, The Effect of Temperature on the Rate of Blood Flow in the Normal and in the Sympathectomized Hand, Am. J. Physiol. -- Leg. Content. 113 (1935) 384-398.

doi:10.1152/ajplegacy.1935.113.2.384.

[27] H. Barcroft, O.G. Edholm, The effect of temperature on blood flow and deep temperature in the human forearm, J. Physiol. 102 (1943) 5-20.

http://www.ncbi.nlm.nih.gov/pmc/articles/PMC1393429/.

[28] J. Hao, P. Ghosh, S.K. Li, B. Newman, G.B. Kasting, S.G. Raney, Heat effects on drug delivery across human skin., Expert Opin. Drug Deliv. 13 (2016) 755-768. doi:10.1517/17425247.2016.1136286.

[29] M.A. Ashburn, L.L. Ogden, J. Zhang, G. Love, S. V Basta, The pharmacokinetics of transdermal fentanyl delivered with and without controlled heat, J. Pain. 4 (2003) 291-297. doi:10.1016/S1526-5900(03)00618-7.

[30] E.E. Lawson, A.N. Anigbogu, A.C. Williams, B.W. Barry, H.G. Edwards, Thermally induced molecular disorder in human stratum corneum lipids compared with a model phospholipid system; FTRaman spectroscopy., Spectrochim. Acta. A. Mol. Biomol. Spectrosc. 54A (1998) 543-58.

[31] D.G. Wood, M.B. Brown, S.A. Jones, Understanding heat facilitated drug transport across human epidermis., Eur. J. Pharm. Biopharm. 81 (2012) 642-649. doi:10.1016/j.ejpb.2012.03.019.

[32] C.L. Silva, S.C.C. Nunes, M.E.S. Eusebio, A.A.C.C. Pais, J.J.S. Sousa, Thermal behaviour of human stratum corneum. A differential scanning calorimetry study at high scanning rates., Skin Pharmacol. Physiol. 19 (2006) 132-139. doi:10.1159/000092593.

[33] J.E. Harrison, P.W. Groundwater, K.R. Brain, J. Hadgraft, Azone ${ }^{\circledR}$ induced fluidity in human stratum corneum. A fourier transform infrared spectroscopy investigation using the perdeuterated 
analogue, J. Control. Release. 41 (1996) 283-290. doi:https://doi.org/10.1016/01683659(96)01348-X.

[34] A. Alonso, N.C. Meirelles, M. Tabak, Lipid chain dynamics in stratum corneum studied by spin label electron paramagnetic resonance., Chem. Phys. Lipids. 104 (2000) 101-111.

[35] M. Kirjavainen, J. Monkkonen, M. Saukkosaari, R. Valjakka-Koskela, J. Kiesvaara, A. Urtti, Phospholipids affect stratum corneum lipid bilayer fluidity and drug partitioning into the bilayers., J. Control. Release. 58 (1999) 207-214.

[36] J.C. La, J.P. Bitll, Thermal conditions which cause skin burns, n.d. http://citeseerx.ist.psu.edu/viewdoc/download?doi=10.1.1.887.1571\&rep=rep1\&type=pdf (accessed April 26, 2019).

[37] T. Gowrishankar, D.A. Stewart, G.T. Martin, J.C. Weaver, Transport lattice models of heat transport in skin with spatially heterogeneous, temperature-dependent perfusion, Biomed. Eng. Online. 3 (2004) 42. doi:10.1186/1475-925X-3-42.

[38] D.P. Otto, M.M. de Villiers, What is the future of heated transdermal delivery systems?, Ther. Deliv. 5 (2014) 961-964. doi:10.4155/tde.14.66.

[39] F. Akomeah, T. Nazir, G.P. Martin, M.B. Brown, Effect of heat on the percutaneous absorption and skin retention of three model penetrants, Eur. J. Pharm. Sci. 21 (2004) 337-345. doi:10.1016/j.ejps.2003.10.025.

[40] T.S. Shomaker, J. Zhang, M.A. Ashburn, Assessing the impact of heat on the systemic delivery of fentanyl through the transdermal fentanyl delivery system., Pain Med. 1 (2000) 225-230.

[41] T.S. Shomaker, J. Zhang, M.A. Ashburn, A pilot study assessing the impact of heat on the transdermal delivery of testosterone., J. Clin. Pharmacol. 41 (2001) 677-682.

[42] T.F. Barkve, K. Langseth-Manrique, J.E. Bredesen, K. Gjesdal, Increased uptake of transdermal glyceryl trinitrate during physical exercise and during high ambient temperature., Am. Heart J. 112 (1986) 537-541.

[43] I.H. Blank, R.J. Scheuplein, D.J. MacFarlane, Mechanism of percutaneous absorption. 3. The effect of temperature on the transport of non-electrolytes across the skin., J. Invest. Dermatol. 49 (1967) 582-589.

[44] K. Ruetzler, B. Sima, L. Mayer, A. Golescu, D. Dunkler, W. Jaeger, M. Hoeferl, J. You, D.I. Sessler, G. Grubhofer, D. Hutschala, Lidocaine/tetracaine patch (Rapydan) for topical anaesthesia before arterial access: a double-blind, randomized trial., Br. J. Anaesth. 109 (2012) 790-796. doi:10.1093/bja/aes254.

[45] T.B. Marriott, M.R. Charney, S. Stanworth, Effects of Application Durations and Heat on the Pharmacokinetic Properties of Drug Delivered by a Lidocaine/Tetracaine Patch: A Randomized, Open-Label, Controlled Study in Healthy Volunteers, Clin. Ther. 34 (2012) 2174-2183. 
doi:10.1016/j.clinthera.2012.08.008.

[46] A. Stier, E. Halekote, A. Mark, S. Qiao, S. Yang, K. Diller, N. Lu, Stretchable Tattoo-Like Heater with On-Site Temperature Feedback Control, Micromachines . 9 (2018). doi:10.3390/mi9040170.

[47] P. Mostafalu, A. Tamayol, R. Rahimi, M. Ochoa, A. Khalilpour, G. Kiaee, I.K. Yazdi, S. Bagherifard, M.R. Dokmeci, B. Ziaie, S.R. Sonkusale, A. Khademhosseini, Smart Bandage for Monitoring and Treatment of Chronic Wounds, Small. 14 (2018) 1703509. doi:10.1002/smll.201703509.

[48] J. Yun, D.H. Lee, J.S. Im, H.-I. Kim, Improvement in transdermal drug delivery performance by graphite oxide/temperature-responsive hydrogel composites with micro heater., Mater. Sci. Eng. C. Mater. Biol. Appl. 32 (2012) 1564-1570. doi:10.1016/j.msec.2012.04.043.

[49] S. Bagherifard, A. Tamayol, P. Mostafalu, M. Akbari, M. Comotto, N. Annabi, M. Ghaderi, S. Sonkusale, M.R. Dokmeci, A. Khademhosseini, Dermal Patch with Integrated Flexible Heater for on Demand Drug Delivery., Adv. Healthc. Mater. 5 (2016) 175-184. doi:10.1002/adhm.201500357.

[50] D. Son, J. Lee, S. Qiao, R. Ghaffari, J. Kim, J.E. Lee, C. Song, S.J. Kim, D.J. Lee, S.W. Jun, S. Yang, M. Park, J. Shin, K. Do, M. Lee, K. Kang, C.S. Hwang, N. Lu, T. Hyeon, D.-H. Kim, Multifunctional wearable devices for diagnosis and therapy of movement disorders., Nat. Nanotechnol. 9 (2014) 397-404. doi:10.1038/nnano.2014.38.

[51] A. Tamayol, A. Hassani Najafabadi, P. Mostafalu, A.K. Yetisen, M. Commotto, M. Aldhahri, M.S. Abdel-Wahab, Z.I. Najafabadi, S. Latifi, M. Akbari, N. Annabi, S.H. Yun, A. Memic, M.R. Dokmeci, A. Khademhosseini, Biodegradable elastic nanofibrous platforms with integrated flexible heaters for on-demand drug delivery., Sci. Rep. 7 (2017) 9220. doi:10.1038/s41598-017-04749-8.

[52] H. Lee, T.K. Choi, Y.B. Lee, H.R. Cho, R. Ghaffari, L. Wang, H.J. Choi, T.D. Chung, N. Lu, T. Hyeon, S.H. Choi, D.H. Kim, A graphene-based electrochemical device with thermoresponsive microneedles for diabetes monitoring and therapy, Nat. Nanotechnol. 11 (2016) 566-572. doi:10.1038/nnano.2016.38.

[53] F. Teodorescu, G. Queniat, C. Foulon, M. Lecoeur, A. Barras, S. Boulahneche, M.S. Medjram, T. Hubert, A. Abderrahmani, R. Boukherroub, S. Szunerits, Transdermal skin patch based on reduced graphene oxide: A new approach for photothermal triggered permeation of ondansetron across porcine skin., J. Control. Release. 245 (2017) 137-146. doi:10.1016/j.jconrel.2016.11.029.

[54] Y. Hao, M. Dong, T. Zhang, J. Peng, Y. Jia, Y. Cao, Z. Qian, Novel Approach of Using Near-Infrared Responsive PEGylated Gold Nanorod Coated Poly(I-lactide) Microneedles to Enhance the Antitumor Efficiency of Docetaxel-Loaded MPEG-PDLLA Micelles for Treating an A431 Tumor., ACS Appl. Mater. Interfaces. 9 (2017) 15317-15327. doi:10.1021/acsami.7b03604. 